Article

\title{
Incorporation of Rheological Characterization in Grinding and Tailings Slurries to Optimize the CMP Magnetic Separation Plant
}

\author{
Galo Brito ${ }^{1,2}$, Oscar Jerez ${ }^{3}$ and Leopoldo Gutierrez ${ }^{1,4, *(1)}$ \\ 1 Department of Metallurgical Engineering, Universidad de Concepción, Concepción 4070371, Chile; \\ gabrito@cmp.cl \\ 2 Compañía Minera del Pacífico (CMP), Vallenar 1611167, Chile \\ 3 Instituto de Geología Económica Aplicada GEA, Universidad de Concepción, Concepción 4070386, Chile; \\ ojerez@udec.cl \\ 4 Water Research Center for Agriculture and Mining (CRHIAM), Universidad de Concepción, \\ Concepción 4070411, Chile \\ * Correspondence: lgutierrezb@udec.cl
}

Citation: Brito, G.; Jerez, O.; Gutierrez, L. Incorporation of Rheological Characterization in Grinding and Tailings Slurries to Optimize the CMP Magnetic Separation Plant. Minerals 2021, 11, 386. https://doi.org/10.3390/ $\min 11040386$

Academic Editor: Saeed Farrokhpay

Received: 27 February 2021

Accepted: 31 March 2021

Published: 5 April 2021

Publisher's Note: MDPI stays neutral with regard to jurisdictional claims in published maps and institutional affiliations.

Copyright: (c) 2021 by the authors. Licensee MDPI, Basel, Switzerland. This article is an open access article distributed under the terms and conditions of the Creative Commons Attribution (CC BY) license (https:// creativecommons.org/licenses/by/ $4.0 /)$.

\begin{abstract}
Compañía Minera del Pacífico (CMP) is the main iron producer on the Pacific coast of the American continent. The Cerro Negro Norte (CNN) operation of CMP is facing important challenges, such as the processing of low-grade ores containing complex gangue minerals which negatively affect the performance of the magnetic separation, grinding and solid-liquid separation stages. CMP is working on a program, aimed at optimizing the efficiency of the CNN plant, which considers a rheological characterization of the slurries produced by the different ores treated, information which will be useful to optimize the performance of the physical separation processes. The objective of this work was to characterize the slurries obtained from the secondary grinding and tailings thickener stages through rheological measurements. The rheological data were correlated with the physical, chemical and mineralogical characteristics of the different geological units (GU) tested. The results show that the rheological flow curves of the slurries taken from the secondary grinding product display a pseudoplastic behavior which follows a Casson model pattern. An exponential model was used to correlate the Casson yield stresses with the solids content of the slurries taken from the secondary grinding product. The results of this fitting process indicate that the yield stresses increase with the $\%-325 \#$ Tyler mesh and with the percentage of minerals with a tendency to generate fines $(\mathrm{MTF}=$ smectite + illite $/$ mica + talc + chlorite + kaolinite $)$, and in contrast the yield stresses decrease with the ore iron grade $(\mathrm{Fe})$. For the tailings characterization, the results of settling rates and turbidity values of the supernatant obtained from tests with different GU samples show no significant differences. A linear regression model was used to correlate the results of yield stresses of compacted tailings with the chemical and mineralogical characteristics of the GU. The results of the fitting process indicate that the MTF content in the head ore samples influence the rheological properties of the tailings, which correlates with the behavior of the secondary grinding product. The increase in the GU iron grades also reduced the Casson yield stress. The experimental results were explained in terms of the microrheological effects and the physicochemical properties of the different types of phyllosilicates existing in the ore samples tested in this work.
\end{abstract}

Keywords: magnetic separation; grinding; tailings iron ores; phyllosilicates; rheology

\section{Introduction}

Compañía Minera del Pacífico (CMP) is the main producer of iron ore in Chile and on the Pacific coast of the American continent. In 2019, CMP produced 10,089 kt of iron and participated in $99 \%$ of Chile's iron ore exports, with the most important products being pellets feed, self-melting and sintered pellets [1,2]. One of CMP's mining operations is 
Cerro Negro Norte (CNN) which is a mine-plant operation located in the Atacama region in northern Chile. The CNN deposit is part of the Chilean Iron Belt and corresponds to a spatial and temporal association between iron oxide-apatite (IOA) and iron oxide copper gold (IOCG) type deposits. CNN started its operations in 2015 with the objective of producing $4000 \mathrm{kt}$ of iron concentrate per year. The company is currently focused on developing a plan to address the challenges that the CNN plant will face in the near future, i.e., low ore grades, and high concentrations of complex gangue mineral species in the ores, which negatively affect the efficiency of the processing plant. CMP is working on a program aimed at optimizing the efficiency of the $\mathrm{CNN}$ plant which considers a rheological characterization of the slurries produced by the different ores treated, information which will be useful to optimize the performance of the physical separation processes. A new process diagram is also projected, as described in Figure 1, which includes stages of primary grinding, rougher magnetic separation, secondary grinding in direct configuration, hydroseparation and classification and finisher magnetic separation. In this new process, the ore previously crushed to $100 \%-3 \mathrm{~mm}$ is first ground in the primary grinding stage to a $\mathrm{P} 80=312 \mu \mathrm{m}$, and then fed to two stages of rougher magnetic separation, i.e., a medium intensity ( 3000 Gauss) and a low intensity stage (1000 Gauss); the rougher concentrate is then ground in the secondary grinding to a P $80=42 \mu \mathrm{m}$, product which is then treated in a hydro-separator to remove slimes; the underflow of the hydro-separator, which still may contain coarse gangue particles, is afterwards classified in a $75 \mu \mathrm{m}$ screen (200 Tyler mesh) and the undersize stream is concentrated in a finisher magnetic separation stage (1000 Gauss) to produce the final iron concentrate. The rougher and finisher tailings, the slimes of the hydro-separator and the coarse fraction of the classifier are sent to thickeners and then to a tailings dump.

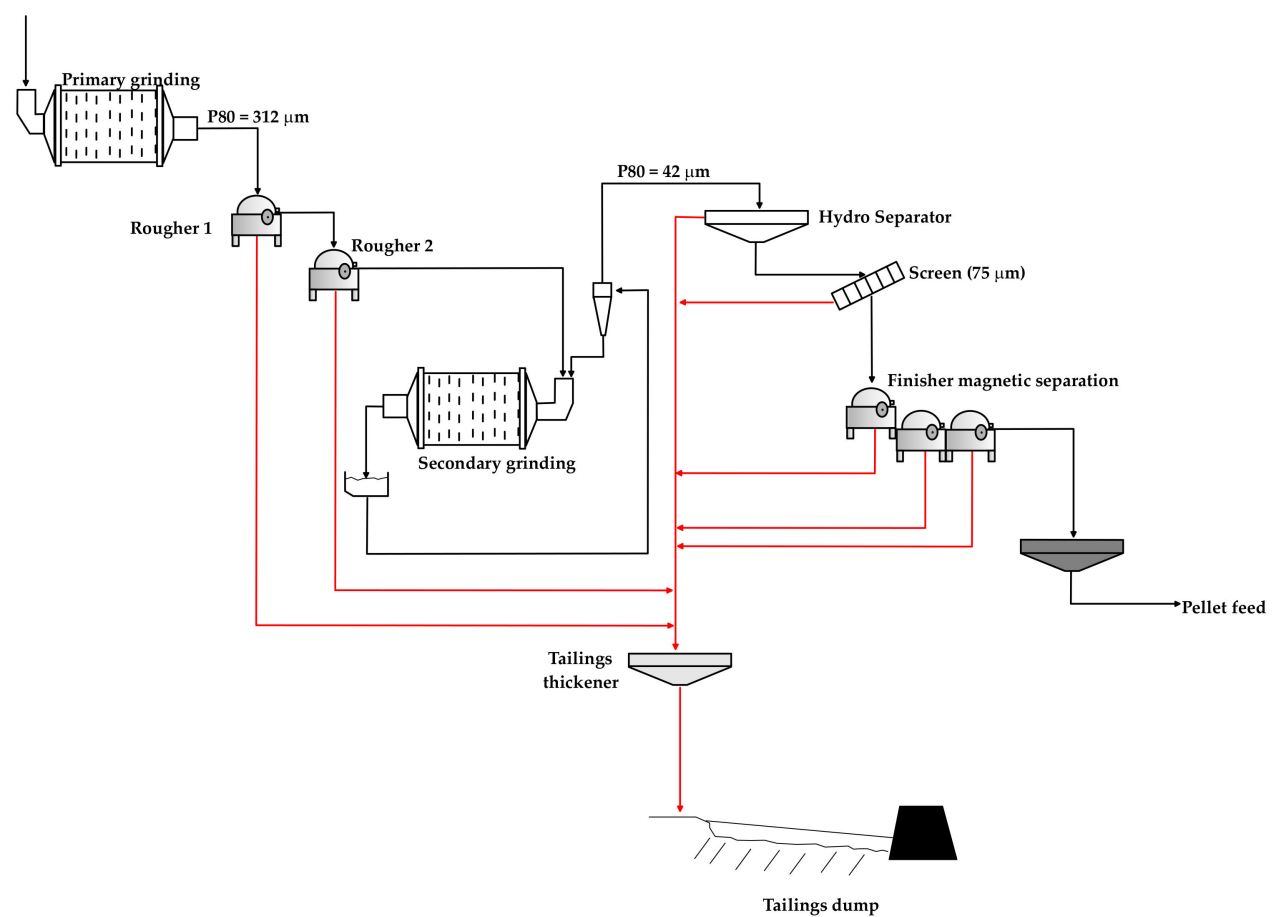

Figure 1. Flowsheet of the projected Cerro Negro Norte (CNN) processing plant.

It is of main relevance for the company to evaluate the performance of the processing plant described in Figure 1 when it is fed with geological units (GU) of varying physical, chemical and mineralogical characteristics. Understanding the rheological behavior of the slurries produced by the different GU is the first step in order to optimize the physical separation stages of the plant, and for the development of geometallurgical models which will help to enhance the plant performance. 
The objective of this work is to characterize the slurries generated using GU of varying physical, chemical and mineralogical characteristics through rheological measurements. The slurries under study were obtained from the secondary grinding product and from the tailing thickener underflow. The rheological data were correlated with the physical, chemical and mineralogical characteristics of the different GU.

\section{Materials and Methods}

\subsection{Samples}

Ore samples of $6 \mathrm{GU}$ (M1 to M6) obtained from different zones of the CNN mine deposit were used in this work. It has to be noted that these samples were taken directly from the mine and then crushed to $100 \%-3 \mathrm{~mm}$ to be used in the experiments as head samples (Figure 1). These GU were defined in $\mathrm{CNN}$ using classification attributes such as iron grade, metallurgical tests, lithology, oxidation zone and spatial location. It should be noted that, according to the block model, these GU represent $94 \%$ of the mass to be processed by CNN during the next 24 years, which justifies their use in this study. Table 1 shows some GU classification attributes, and Table 2 shows the X-ray diffraction (XRD) mineralogical composition of samples M1 to M6. Slurries were prepared using the process water of the CNN's processing plant. The main characteristics of the process water are displayed in Table 3.

Table 1. Geological units (GU) classification attributes of samples M1 to M6.

\begin{tabular}{ccccc}
\hline \multirow{2}{*}{ Sample } & \multicolumn{4}{c}{ GU Classification Attributes } \\
\cline { 2 - 4 } & Fe Grade (\%) & Grade & Oxidation Zone & Lithology \\
\hline M1 & 27.63 & Low & Oxided & Metandesite altered \\
M2 & 32.46 & Medium & Primary & Metandesite altered \\
M3 & 38.44 & High & Oxided & Metandesite \\
M4 & 29.19 & Low & Primary & Metandesite \\
M5 & 31.96 & Medium & Oxided & Metandesite \\
M6 & 42.57 & High & Primary & Metandesite \\
\hline
\end{tabular}

Table 2. X-ray diffraction (XRD) mineralogical composition of samples M1 to M6.

\begin{tabular}{|c|c|c|c|c|c|c|c|c|c|c|c|c|c|}
\hline \multirow[b]{2}{*}{ Sample } & \multicolumn{12}{|c|}{ Mineralogical Composition (\%) } & \multirow[b]{2}{*}{ MTF } \\
\hline & 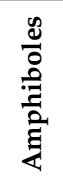 & 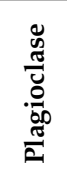 & 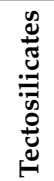 & 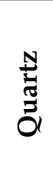 & 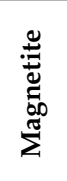 & & 苞 & 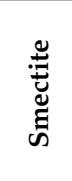 & 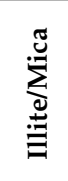 & $\frac{\breve{U}}{\widetilde{\sigma}}$ & $\frac{\stackrel{0}{0}}{\stackrel{0}{c}}$ & 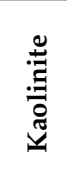 & \\
\hline M1 & 4.8 & 16.8 & 5.4 & 0.5 & 56.8 & 15.7 & 0.13 & 0.31 & 0.11 & 0.11 & 0.48 & 0.19 & 1.20 \\
\hline M2 & 3.5 & 18.4 & 0.3 & 0.6 & 68.4 & 8.9 & 0.16 & 0.23 & 0.11 & 0.11 & 0.40 & 0.16 & 1.00 \\
\hline M3 & 1.8 & 16 & 0.3 & 0.4 & 72.5 & 8.6 & 0.00 & 0.17 & 0.10 & 0.00 & 0.56 & 0.13 & 0.96 \\
\hline M4 & 2.3 & 25.2 & 0.3 & 0.3 & 59.3 & 8.9 & 0.00 & 0.22 & 0.13 & 0.09 & 0.64 & 0.19 & 1.26 \\
\hline M5 & 10.7 & 20.6 & 0.2 & 0.1 & 61.1 & 7.3 & 0.00 & 0.19 & 0.11 & 0.07 & 0.61 & 0.16 & 1.14 \\
\hline M6 & 1.7 & 17.4 & 0 & 0 & 75.8 & 5 & 0.15 & 0.18 & 0.09 & 0.07 & 0.51 & 0.11 & 0.97 \\
\hline
\end{tabular}

Table 3. CNN process water characteristics.

\begin{tabular}{ccc}
\hline Parameter & Magnitude & Units \\
\hline Alkalinity MO & 15 & ppm \\
Total hardness & 791 & ppm \\
Calcic hardness & 717 & ppm \\
Total solids & 2400 & ppm \\
Solids in suspension & 250 & ppm \\
Chlorides & 420 & ppm \\
Al & Not detected & ppm \\
Ca & 416 & Not detected \\
\hline
\end{tabular}


Table 3. Cont.

\begin{tabular}{ccc}
\hline Parameter & Magnitude & Units \\
\hline $\mathrm{Cu}$ & Not detected & \\
$\mathrm{Fe}$ & 0.04 & $\mathrm{ppm}$ \\
$\mathrm{pH}$ & 7.6 & $\mathrm{NTU}$ \\
Turbidity & 0.58 & $\mathrm{~N}$ \\
\hline
\end{tabular}

\subsection{Procedures}

\subsubsection{Slurry Preparation}

The process diagram described in Figure 1 was simulated at laboratory-scale following the flowsheet presented in Figure 2, which includes stages of primary grinding (1), rougher magnetic separation (2), secondary grinding (1), hydro-separation (1), classification (1) and finisher magnetic separation (1). Slurries from sampling points A and B representing the secondary grinding product and tailings, respectively, were characterized through rheological measurements and settling tests in the case of the tailings. The operating conditions and the equipment used in this work are described in Table 4.

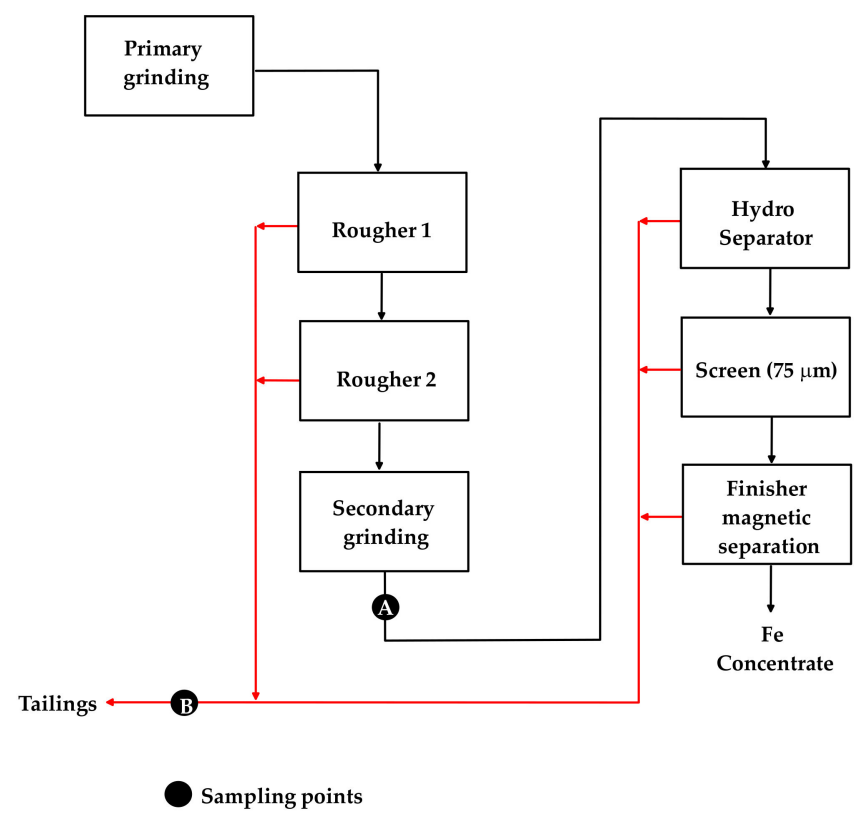

Figure 2. Process diagram used at laboratory-scale to generate the slurries characterized in the study.

Table 4. Operating conditions and equipment.

\begin{tabular}{|c|c|c|c|c|}
\hline Stage & Equipment & Dimensions & Ore and Ball Charge & Pulp Conditions \\
\hline Primary grinding & Torque mill ( $\omega=47 \mathrm{rpm})$, Salas Ing. & $\begin{array}{l}\mathrm{D}^{1}: 46 \mathrm{~cm} \\
\mathrm{~L}^{1}: 40 \mathrm{~cm}\end{array}$ & $\begin{array}{c}20 \mathrm{~kg} \text { ore; balls charge } \\
25 \mathrm{~kg} \text { of } 1.5^{\prime \prime}, 21 \mathrm{~kg} \text { of } 1.25^{\prime \prime} \\
20 \mathrm{~kg} \text { of } 1^{\prime \prime} \text { and } 21 \mathrm{~kg} \text { of } 0.75^{\prime \prime}\end{array}$ & $\begin{array}{l}55 \% \text { solids content, } \\
47 \mathrm{rpm}\end{array}$ \\
\hline $\begin{array}{l}\text { Rougher magnetic } \\
\text { separator } 1\end{array}$ & $\begin{array}{l}\text { Eriez-Salas drum magnetic separator } \\
(1000 \text { Gauss, } \omega=30 \mathrm{rpm})\end{array}$ & $\begin{array}{l}\mathrm{D}^{1}: 30.4 \mathrm{~cm} \\
\mathrm{~L}^{1}: 19 \mathrm{~cm}\end{array}$ & & $\begin{array}{c}30 \% \text { solids content, } \\
4.6 \mathrm{~L} / \mathrm{min}\end{array}$ \\
\hline $\begin{array}{l}\text { Rougher magnetic } \\
\text { separator } 2\end{array}$ & $\begin{array}{l}\text { Eriez-Salas drum magnetic separator } \\
\quad(750 \text { Gauss, } \omega=30 \mathrm{rpm})\end{array}$ & $\begin{array}{l}\mathrm{D}^{1}: 30.4 \mathrm{~cm} \\
\mathrm{~L}^{1}: 19 \mathrm{~cm}\end{array}$ & & $\begin{array}{c}30 \% \text { solids content, } \\
4.6 \mathrm{~L} / \mathrm{min}\end{array}$ \\
\hline Secondary grinding & Marcy ball mill & $\begin{array}{l}\mathrm{D}^{1}: 30.5 \mathrm{~cm} \\
\mathrm{~L}^{1}: 30.5 \mathrm{~cm}\end{array}$ & $\begin{array}{c}5 \mathrm{~kg} \text { ore; balls charge } \\
17.5 \mathrm{~kg} \text { of } 1.25^{\prime \prime}, 9.8 \mathrm{~kg} 1.0^{\prime \prime}, \\
4.2 \mathrm{~kg} \text { of } 0.75^{\prime \prime} \text { and } 3.5 \mathrm{~kg} \text { of } 0.5^{\prime \prime}\end{array}$ & $\begin{array}{l}80 \% \text { solids content, } \\
70 \mathrm{rpm}\end{array}$ \\
\hline Hydro-separation & $\begin{array}{l}\text { Hydro-separator including magnetic } \\
\text { flocculator }\end{array}$ & $\begin{array}{l}\mathrm{D}^{1}: 41 \mathrm{~cm} \\
\mathrm{H}^{1}: 31.3 \mathrm{~cm}\end{array}$ & & $13 \%$ solids content \\
\hline Screen & 200\# screen & & & \\
\hline Finisher separation & $\begin{array}{l}\text { Eriez-Salas drum magnetic separator } \\
\qquad(750 \text { Gauss, } \omega=30 \mathrm{rpm})\end{array}$ & $\begin{array}{l}\mathrm{D}^{1}: 30.4 \mathrm{~cm} \\
\mathrm{~L}^{1}: 19 \mathrm{~cm}\end{array}$ & & $\begin{array}{c}30 \% \text { solids content, } \\
4.6 \mathrm{~L} / \mathrm{min}\end{array}$ \\
\hline
\end{tabular}

${ }^{1}$ D: diameter; L: length; H: height; $\omega$ : rotation speed. 


\subsubsection{Rheological Characterization of the Secondary Grinding Product}

Preliminary tests showed that, depending on the experimental conditions, the product of the secondary grinding stage contained $+0.1 \mathrm{~mm}$ particles which made it unsuitable for the use of concentric cylinders to measure rheology. For this reason, the rheological characterization of the secondary grinding product was performed using the method referred to as the infinity gap approach. This method is based on the work done by Krieger and Maron (1952, 1953, 1954) [3-5] and Krieger and Woods (1966) [6], who solved the basic equation for coaxial rotational rheometers for various sets of boundary conditions, which resulted in Equation (1).

$$
\Omega=\frac{1}{2} \int_{\tau_{1}}^{\tau_{2}} f(\tau) \frac{d \tau}{\tau}
$$

where $\Omega$ is the angular velocity of the inner or outer cylinder, $f(\tau)=\dot{\gamma}$ is the shear rate at the point of measurement of the shear stress $\tau$ and $\tau_{1}$ and $\tau_{2}$ are the shear stresses exerted on the inner and outer cylinders, respectively. This is a general expression valid for steady flow in rotational rheometers which can be solved for the special case where a cylindrical bob rotates in an infinite cup [7], a configuration in which the presence of $+0.1 \mathrm{~mm}$ particles does not significantly affect the quality of the rheological measurements. In the infinite gap approach configuration, the shear stress on the cup $\left(\tau_{2}\right)$ becomes zero in Equation (1), and the resulting expression can be differentiated with respect to the shear stress on the bob $\left(\tau_{1}\right)$ to obtain Equation (2), which indicates that the shear rate can be obtained from the slope of a graph of $\operatorname{Ln}(\Omega)$ versus $\operatorname{Ln}\left(\tau_{1}\right)$. It must be noted that although Equation (2) assumes complete shearing across the infinite gap between the bob and cup, it is also valid for suspensions that display yield stress [7].

$$
\dot{\gamma}_{1}=2 \Omega \frac{d(\operatorname{Ln}(\Omega))}{d\left(\operatorname{Ln}\left(\tau_{1}\right)\right)}
$$

In this study, rheological flow curves ( $\tau$ vs. $\dot{\gamma}$ ) of slurries taken from the secondary grinding stage (sampling point A in Figure 2) were measured using the infinite gap approach. The rotating surface (the bob) in these experiments was a vane of $0.5 \mathrm{~cm}$ diameter and $6 \mathrm{~cm}$ height, dimensions that were chosen to meet the recommendations by Fisher et al., (2007) [8] to reduce end effects. A Haake Rotovisco VT550 (ThermoFisher, Waltham, MA, USA) rotational viscometer was used with the vane rotating at different rotational speeds in a beaker of $30 \mathrm{~cm}$ diameter and $20 \mathrm{~cm}$ height. The shear stress was calculated using Equation (3), which assumes that the slurry sample yields on a cylindrical surface of radius equal to the vane radius $\left(r_{v}\right)$, and that the shear stress exerted on the top and bottom ends of the vane is negligible with respect to the shear stress on the cylindrical surface.

$$
\tau=\frac{2 T}{\pi D_{v}^{2} H_{v}}
$$

where $T$ is torque, and $D_{v}$ and $H_{v}$ are the vane diameter and height, respectively. The equilibrium $T$ was measured at varying values of $\Omega$ and Equation (2) was used to calculate the shear rates.

The slurry samples obtained from the secondary grinding (sampling point A in Figure 2) were tested at 3 different conditions of particle size, i.e., 50, 60 and 70\%-325\# Tyler mesh $(45 \mu \mathrm{m})$. At each condition of particle size, 4 different values of solids contents were tested, i.e., $76,78,80$ and $82 \%$. It has to be noted that the solids contents were selected based on the industrial conditions of CNN. The rheological data were fitted using the Casson model presented in Equation (4) [9] from which the Casson yield stress was obtained.

$$
\tau^{1 / 2}=\tau_{c}^{1 / 2}+\left(\eta_{p l} \dot{\gamma}\right)^{1 / 2}
$$

where $\tau_{c}$ is the Casson yield stress and $\eta_{p l}$ is the equilibrium viscosity at high shear rates. 
It is known that particles settling is an important source of errors that has to be taken into account during the design of rheological experiments for slurries of particles of high density suspended in low viscosity suspensions [10]. In this situation, settling will take place and the solids concentration will vary along the vertical axis of the concentric cylinder rheometer. Consequently, the torque measured on the moving cylinder will not represent the behavior of the overall suspension and the results will be erroneous. In this work, the slurry samples obtained from the secondary grinding had high solids concentrations ( $>76 \%$ by weight) and no settling was observed during the period of time of the rheological experiments.

\subsubsection{Settling Tests and Yield Stress of Tailings}

Samples of tailings obtained from sampling point B in Figure 2 were subjected to settling tests, using $25 \mathrm{~g} / \mathrm{t}$ of flocculant IXOFLOC 1920 AP (provided by IXOM, Centennial, $\mathrm{CO}, \mathrm{USA})$. These tests were performed in $1 \mathrm{~L}$ glass cylinders at $\mathrm{pH} 8.5$, adjusted using lime, and at variable compaction times of $0.25,0.50,1.00$ and $24 \mathrm{~h}$. Due to the characteristics of the process, in particular the contribution of water coming from the hydro-separator, the tailings slurries were strongly diluted and had a solids concentration of approximately $5 \%$.

The yield stresses of the compacted tailings were measured using the vane method [11,12]. In this method, the vane is gently introduced into the slurry and rotated at a constant speed of $0.1 \mathrm{rpm}$ to measure the torque required to keep the rotational speed constant as a function of time.

The curve obtained from the vane test usually shows a linear relationship between torque and time at the beginning, and then a non-linear relationship until the maximum torque $\left(T_{m}\right)$ is reached. Nguyen and Boger $(1983,1985)$ [11,12] proposed that yielding occurred at $T_{m}$, the point at which the interparticle network broke down completely and the energy needed to keep the rotational speed constant decreased. Nguyen and Boger (1985) [12] proposed that the total torque exerted on the cylindrical surface generated by the vane at $T_{m}$ could be correlated with the yield stress according to Equation (5).

$$
T_{m}=\left(\frac{\pi}{2} D_{v}^{2} \tau_{0}\right) H_{v}+4 \pi \int_{0}^{D_{v} / 2} \tau_{e}(r) r^{2} d r
$$

where $r$ is the vane radius, $\tau_{0}$ is the yield stress and $\tau_{e}(r)$ is a radial stress distribution function at the top and bottom ends of the vane. Equation (5) shows that if yield stress measurements are performed using vanes of different heights and constant diameters, a plot of $T_{m}$ versus $H_{v}$ is a straight line with the intercept equal to the integral term, and the yield stress can be calculated from the slope $\left(\frac{\pi}{2} D_{v}^{2} \tau_{0}\right)$.

In this work, the vane procedure was applied using 4 different 4-bladed vanes connected to a Haake VT550 rheometer (ThermoFisher, Waltham, MA, USA). The vanes had a constant $D_{v}$ of $2.0 \mathrm{~cm}$, and different $H_{v}$ of $3.0,4.0,5.0$ and $6.0 \mathrm{~cm}$. The tested slurry samples were placed in a beaker in which the vanes were gently introduced into the slurries. The beaker to vane height ratios, and beaker to vane diameter ratios were chosen to be larger than 3 to reduce the rigid boundary effects [11-14]. In this work, the compacted tailings displayed solids concentrations higher than $65 \%$ by weight, and settling was not observed during the period of time in which the vane test was applied.

\section{Results}

\subsection{Rheological Characterization of Secondary Grinding Product}

Figures 3 and 4 show the rheological flow curves of slurries obtained from the secondary grinding stage prepared using samples M1 to M3, and M4 to M6, respectively. As was previously indicated, these tests were carried out at different particle sizes (\% - 325\# Tyler Mesh). Some data points at a high solids content are missed, because at these conditions the measured torque exceeded the maximum achievable by the Haake Rotovisco VT550 rheometer. The rheological flow curves show that all the slurries tested display a pseudoplastic behavior and that the experimental data can be reasonably fitted using the 
Casson model (Equation (4)). Figure 5 shows the Casson yield stresses as a function of the solids contents of the slurries taken from the secondary grinding product. Yield stresses increased with solids content and with decreasing particle size (\% - 325\# Tyler mesh increase), which agrees with the fundamentals of the rheology of mineral suspensions [15].

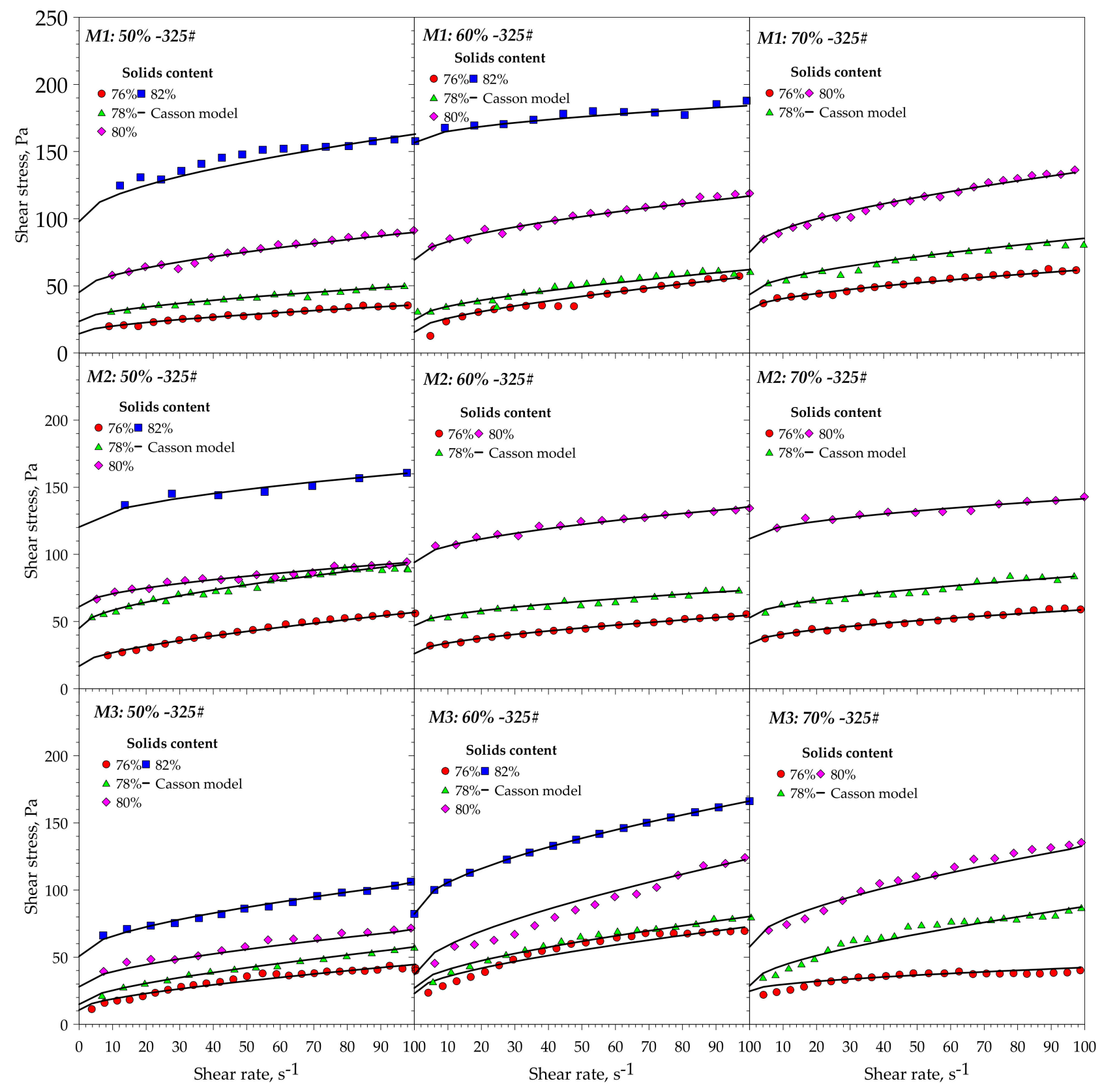

Figure 3. Rheological flow curves of slurries obtained from the secondary grinding stage which were prepared using samples M1 to M3 ground to different particle sizes. 


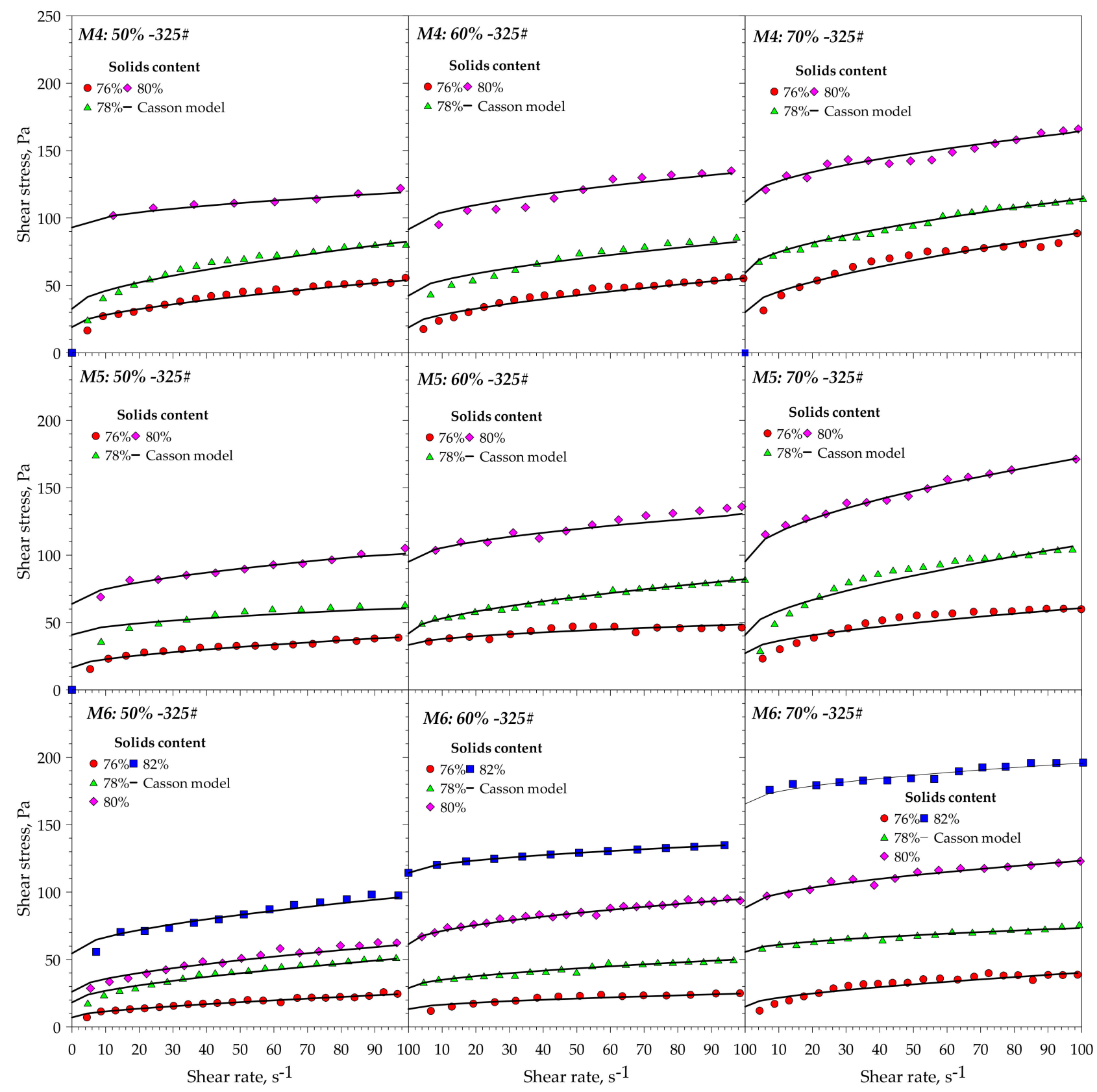

Figure 4. Rheological flow curves of slurries obtained from the secondary grinding stage which were prepared using samples M4 to M6 ground to different particle sizes. 


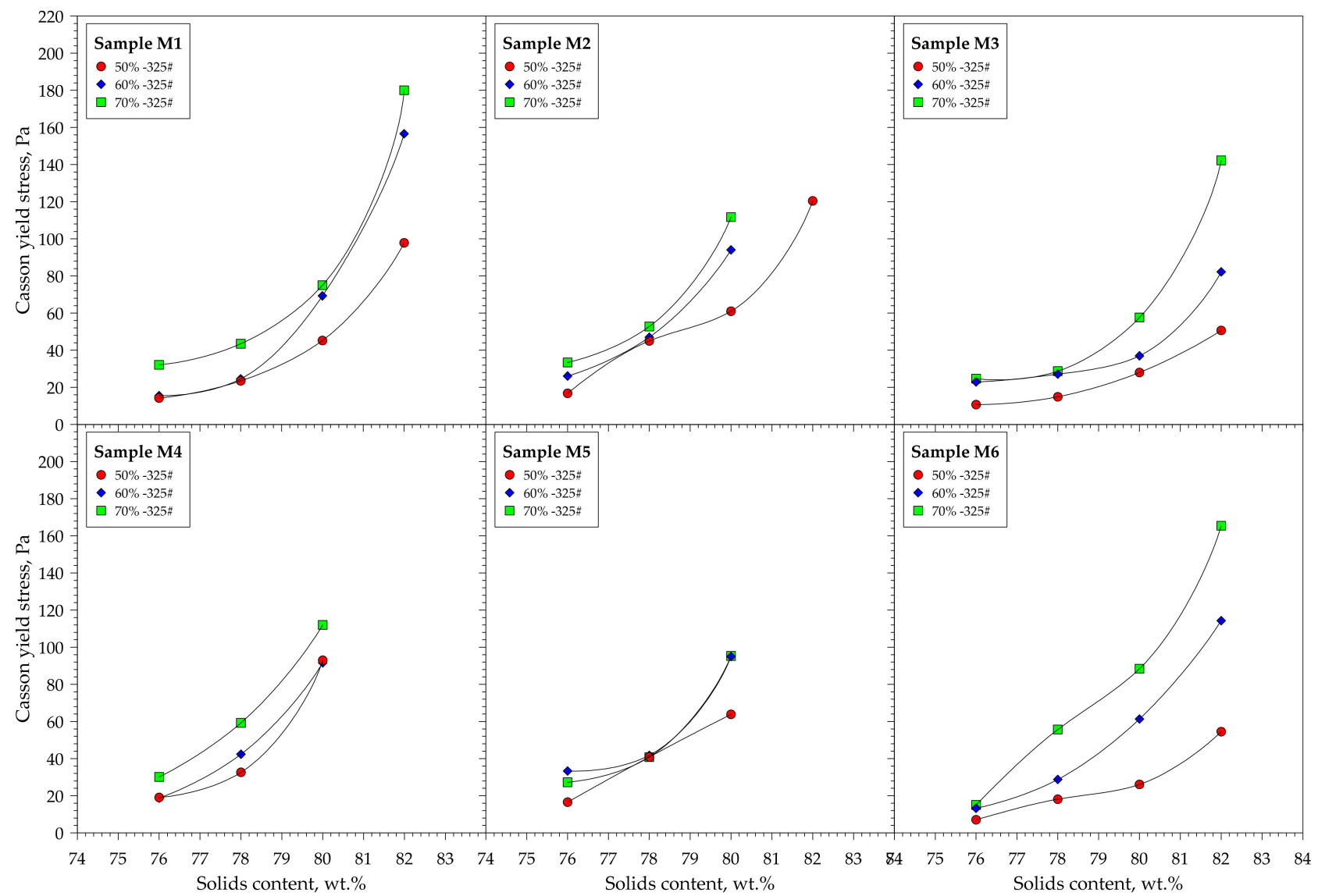

Figure 5. Casson yield stress as function of solids content of slurries obtained from the secondary grinding stage prepared using samples M1 to M6 ground to different particle sizes.

An exponential model presented in Equation (6) was used to correlate the Casson yield stress with the solids content of the slurries taken from the secondary grinding product.

$$
\tau=a e^{b S}
$$

where $S$ is the solids content, and $a$ and $b$ are empirical constants which depend on particle size and on the chemical and mineralogical characteristics of the GU (Tables 1 and 2). Constants $a$ and $b$ were correlated with the characteristics of the ore samples using linear regression models, as shown in Equations (7) and (8).

$$
\begin{gathered}
a=A_{0}+A_{1} X_{1}+A_{2} X_{2}+\cdots+A_{n} X_{n} \\
b=B_{0}+B_{1} X_{1}+B_{2} X_{2}+\cdots+B_{n} X_{n}
\end{gathered}
$$

where $X i$ and $A i / B i$ are ore physical/chemical/mineralogical characteristics and experimental fitting constants, respectively. Table 5 displays the values of $X i$ and $A i / B i$, and Figure 6 shows the comparison between the yield stresses obtained using Equation (6) and the experimental values. The results of the fitting process indicate that constants $A i$ and $B i$, and as a result the yield stress, increase with the $\%-325 \#$ Tyler Mesh and with the percentage of minerals with a tendency to generate fines (MTF), and in contrast these parameters decrease with the ore iron grade $(\mathrm{Fe})$. The correlation of the concentrations of amphiboles, plagioclase, tectosilicates and magnetite with the yield stress is evident, but it is not so easy to be explained at this stage of the research program. 
Table 5. Physical, chemical and mineralogical characteristics of the ore samples $X i$, which influence the yield stress and the experimental fitting constants $\mathrm{Ai} / \mathrm{Bi}$.

\begin{tabular}{cccc}
\hline $\boldsymbol{i}$ & $\boldsymbol{X} \boldsymbol{i}$ & $\boldsymbol{A i}$ & $\boldsymbol{B i}$ \\
\hline 0 & & $5.0 \times 10^{-7}$ & $-1.2 \times 10^{-1}$ \\
\hline 1 & $-325 \#, \%$ & $2.1 \times 10^{-10}$ & $2.5 \times 10^{-4}$ \\
\hline 2 & Amphiboles, $\%$ & $-3.9 \times 10^{-9}$ & $3.1 \times 10^{-3}$ \\
\hline 3 & Plagioclase, $\%$ & $-9.1 \times 10^{-9}$ & $7.0 \times 10^{-3}$ \\
\hline 4 & Tectosilicates, $\%$ & $-1.5 \times 10^{-8}$ & $1.1 \times 10^{-2}$ \\
\hline 5 & Magnetite, $\%$ & $-3.6 \times 10^{-9}$ & $3.4 \times 10^{-3}$ \\
\hline 6 & Fe, \% & $-1.5 \times 10^{-9}$ & $-6.3 \times 10^{-6}$ \\
\hline 7 & MTF, \% & $2.4 \times 10^{-9}$ & $8.7 \times 10^{-4}$ \\
\hline
\end{tabular}

$\overline{\text { MTF }}=$ minerals with a tendency to generate fines $=$ smectite + illite $/$ mica + talc + chlorite + kaolinite .

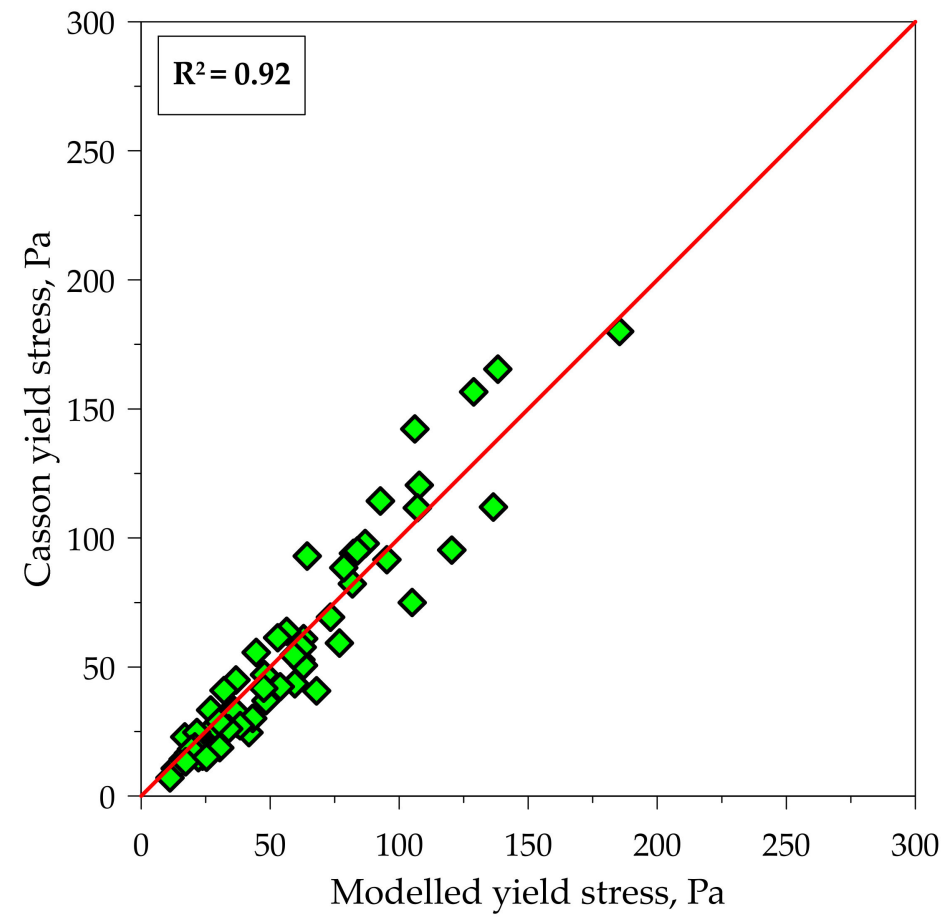

Figure 6. Comparison between the experimental Casson yield stress and values obtained using Equation (6).

\subsection{Settling Tests and Rheological Characterization of Tailings}

Figure 7 shows the position of the pulp/water interface as a function of time during the initial $15 \mathrm{~s}$ of the settling tests. The settling rate calculated from the slope of the linear section of the curve (initial $3 \mathrm{~s}$ ), and the turbidity of the supernatant after $12 \mathrm{~h}$ are displayed in the insert. The analysis of the average values and the standard deviations of these two parameters indicate that there are no significant differences for the tailings obtained by feeding the plant with different GU. It is important to note that the high settling rates in this case are due to the low solids contents of the tailings. 


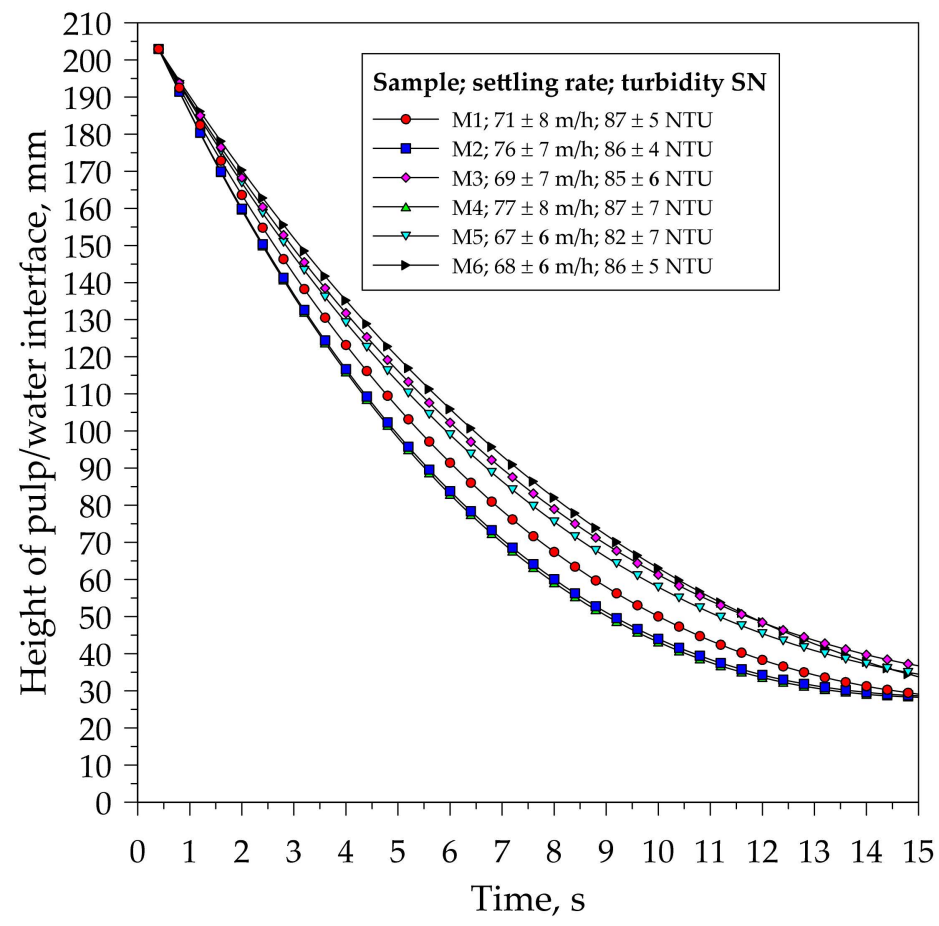

Figure 7. Position of the pulp/water interface as a function of time for the initial $15 \mathrm{~s}$, as measured from settling tests of tailings taken from point B in Figure 2.

Figure 8 shows the Casson yield stresses of the compacted tailings as a function of solids contents. The results show a wide variety of rheological behavior of the tailings slurries obtained from the processing of the different GU.

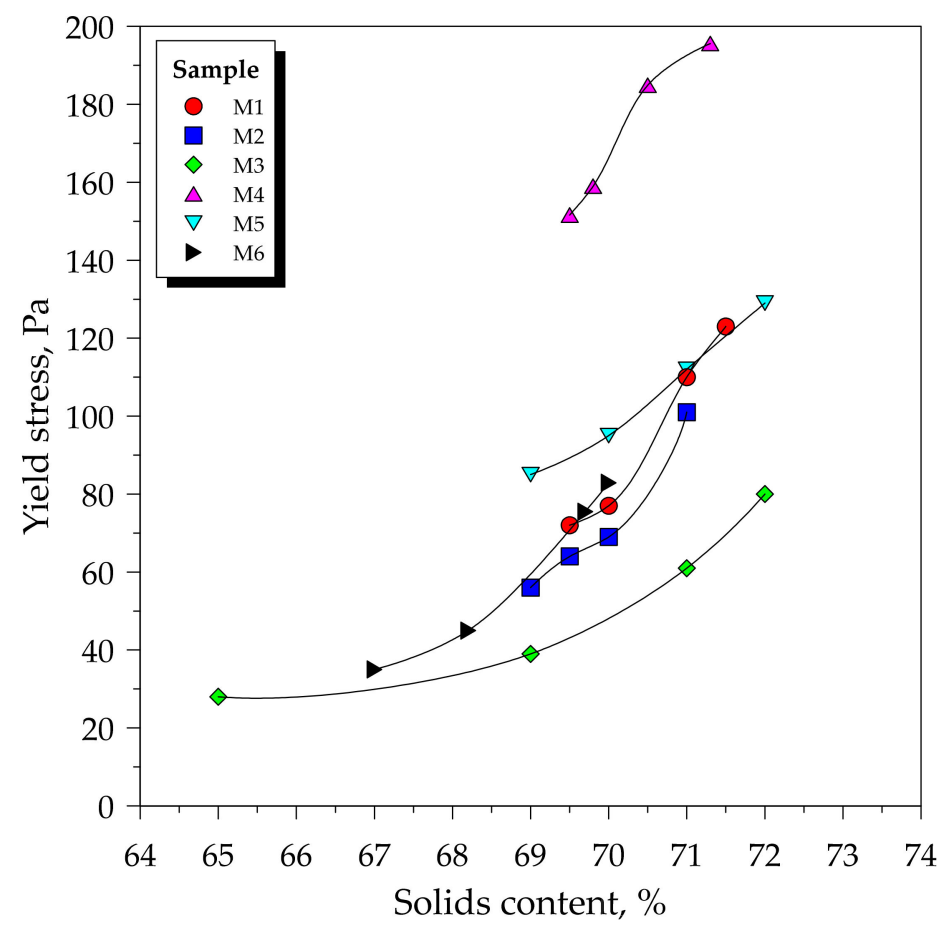

Figure 8. Casson yield stresses of compacted tailings as a function of solids content.

The best fitting of the experimental values of yield stresses was obtained using Equation (9). Figure 9 shows the comparison between the experimental yield stresses of tailings and the values obtained from Equation (9). The results of the fitting process 
indicate that the solids concentration, MTF content in the head ore samples and the ore grade influence the rheological properties of the tailings, which correlates with the behavior of the secondary grinding product.

$$
\tau_{0}=-844.9+11.1 \cdot S-F e+9.9 \cdot M T F
$$

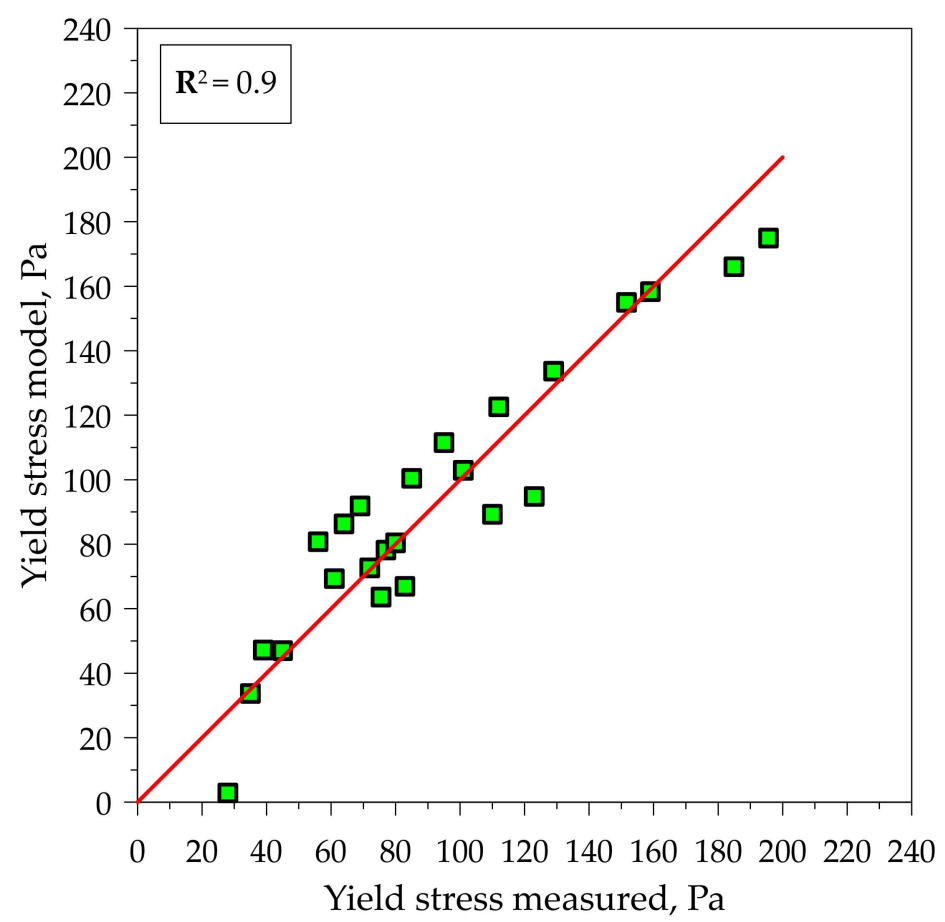

Figure 9. Comparison between the experimental Casson yield stress of tailings and the values obtained using Equation (9).

\section{Discussion}

The rheological behavior of suspensions of particles dispersed in a continuous medium depends on the phenomena taking place at an inter-particle scale, which are the so-called micro-rheological effects. The macroscopic rheological behavior can be predicted from the microscopic interactions between the particles dispersed in suspension, phenomena which is the study subject of micro-rheology [16,17]. Klein (1992) [10] distinguished four micro-rheological effects, i.e., hydrodynamic, electro-viscous, aggregation and granuloviscous. The hydrodynamic effects mainly occur from the resistance produced as a result of the presence of dispersed particles and from the liquid squeezing that takes place as particles approach each other; the electro-viscous effects arise from the interactions between electrical double layers generated around the particles, which affects energy dissipation; the aggregation effects are caused by the action of attractive interparticle forces (e.g., van der Waals forces); and finally, the granulo-viscous effects are related to physical interactions between particles such as particle impacts, inter-particle friction and particle packing. The relative importance of these micro-rheological effects depends on various properties of the suspension that can be classified as physico-mechanical, i.e., solid content, density, shape, size and size distribution of the particles, and physico-chemical variables, i.e., $\mathrm{pH}$, ions, surfactants and other chemicals [18]. The electro-viscous and aggregation effects are more important at small particle sizes $(<20 \mu \mathrm{m})$ with both effects being more significant at high solid contents.

The experimental results obtained in this work indicate that the rheological behavior of the slurries treated strongly depends on the physical, chemical and mineralogical characteristics of the GU head samples. The solids concentration, which is a physico-mechanical variable, strongly affects the yield stresses of the studied slurries; the iron grade also correlates with the rheological data, most likely because this chemical variable is indirectly 
related to mineralogy and in particular to the concentrations of plagioclase and tectosilicates. The concentration of minerals with a tendency to generate fines (phyllosilicates) also affects the experimental yield stress, which is in agreement with what is expected from the micro-rheology theory. Previous studies showed that the presence of phyllosilicates particles dispersed in suspension strongly affected pulp rheology and the efficiency of the mineral processing plants [19-25]. The problems caused by dispersed phyllosilicates particles are usually reduced by doing slurry dilution, which reduces pulp viscosity and disperses fines and ultra-fines. In some cases, the blending of phyllosilicate-bearing ores with less problematic ores is also considered, but this procedure is sometimes limited to mine planning definitions. Phyllosilicates are classified into four groups: serpentine group, clay minerals group, mica group and chlorite group [26], among which minerals of the clays (smectite and kaolinite), mica and chlorite groups were present in the samples tested in this work.

Clay minerals can be described as soft anisotropic and hydrated phyllosilicates, usually present in suspension as small plate-like particles that comprise unit layers stacked like a deck of cards, with a crystal structure of units consisting of sheets of tetrahedrally coordinated silica in combination with octahedral alumina or magnesia [27-30]. Clay mineral particles are highly anisotropic, irregular and heterogeneous in shape, with $\mathrm{pH}$ dependent charges on the faces and edges, different modes of aggregation and a high specific surface and cation exchange capacity in the case of swelling clays. All these particularities of the clay minerals strongly influence pulp rheology through mainly electroviscous and aggregation effects, which was previously reported by Uribe et al., (2016) [18]. Different species of clay minerals have a diverse type of behavior when they are dispersed in aqueous solutions [31-33]. Kaolinite and smectites are typically-found clay minerals. Kaolinite is a 1:1 clay consisting of alternating layers of silica tetrahedra and aluminum hydroxide octahedral (T-O), which are held tightly together by hydrogen bonding, which explains why kaolinite swelling in water is minor [34]; kaolinite particles have two different surfaces created during particle breakage, i.e., the basal silica-like faces which are negatively charged over a wide range of $\mathrm{pH}$, and the alumina-like edges which are positively charged on the neutral-acidic range of $\mathrm{pH}$ [35-38], which explains the tendency of these particles to aggregate and affect the rheological properties of mineral suspensions. Smectites belong to the 2:1 layer clay minerals, and a single platelet is composed of three layers where one octahedral aluminum-oxygen layer is sandwiched between two tetrahedral silicon-oxygen layers $[28,34]$. These mineral particles can also be modeled as laminar particles, with faces and edges with the basal silica-like layers carrying a permanent negative charge, and the edges' charge depending on $\mathrm{pH}$ [24]. Distinctive properties of smectites are swelling and low critical coagulation concentrations (cK) [31], which explains why these types of clay minerals strongly affect rheology. Other phyllosilicates such as micas, talc and chlorite are also anisotropic and generate aggregation, which also affects rheology.

As is presented in this work, the rheological behavior of the slurries obtained from the secondary grinding product and from the tailing thickener underflow depended on the physical, chemical and mineralogical characteristics of the head samples. The rheological data show a correlation with the solids concentrations, the MTF and with the ore iron grade. The effect of the MTF can be explained by the physicochemical characteristics of the different phyllosilicates, which comprise this group which strongly affect the microrheological effects and thus the macroscopic behavior of the slurries. The fact that yield stress values decrease as iron grade increases has to do with the fact that there is an inverse relationship between grade and the MTF content, as can be seen in Table 2. The different physical, chemical and mineralogical characteristics of the ores to be treated in the CNN processing plant will strongly affect the performance of the grinding, and the magnetic and solid-liquid separation stages. A research program intended to study the efficiency of the different unit operations of the CNN processing plant under different physical, chemical and mineralogical conditions is undergoing. As was previously said, an understanding of the rheological behavior of the iron ore slurries is the first step to optimize the physical separation stages of the $\mathrm{CNN}$ plant, and to develop new geometallurgical models. 


\section{Conclusions}

The rheological flow curves of slurries obtained from the secondary grinding product displayed a pseudoplastic pattern, and the experimental data were reasonably fitted using the Casson model.

An exponential model was used to correlate the Casson yield stresses with the solids content of the slurries taken from the secondary grinding product. It was shown that the yield stresses increased with the solids concentration, \% - 325\# Tyler mesh, and with the percentage of minerals with a tendency to generate fines (MTF); in contrast, the yield stresses decreased with the ore iron grade $(\mathrm{Fe})$. Amphiboles, plagioclase, tectosilicates and magnetite affect the yield stress, but further work is needed to better understand this observed experimental correlation.

The results of settling tests and the rheological characterization of tailings showed that the settling rates and turbidity values of the supernatant measured from tests using different head ore samples showed no significant differences. A linear regression model was used to correlate the results of yield stress of the compacted tailings with the physical, chemical and mineralogical characteristics of the ore samples. The results of the fitting process indicate that the solids concentration, the MTF content and the iron grade ore strongly influence the rheological properties of the tailings, which correlates with the behavior of the secondary grinding product.

The experimental results were explained in terms of the microrheological effects and of the physicochemical properties of the different types of phyllosilicates existing in the ores samples tested in this work.

As was previously said, an understanding of the rheological behavior of the iron ore slurries is the first step to optimize the physical separation stages of the $\mathrm{CNN}$ plant, and to develop new geometallurgical models.

Author Contributions: Conceptualization, G.B. and L.G.; methodology, G.B. and L.G.; validation, G.B., L.G. and O.J.; formal analysis, G.B., L.G. and O.J.; investigation, G.B.; writing-original draft preparation, G.B.; writing — review and editing, G.B., L.G. and O.J.; supervision, L.G. All authors have read and agreed to the published version of the manuscript.

Funding: This research was funded by Compañía Minera del Pacífico CMP.

Data Availability Statement: Not applicable.

Acknowledgments: The authors acknowledge the financial support of the Water Research Centre for Agriculture and Mining (CRHIAM) of the Universidad de Concepcion sponsored by the ANID/FONDAP/15130015 project. Leopoldo Gutierrez thanks ANID/FONDEF IDeA I+D/ID18I10117 project. Galo Brito thanks Compañía Minera del Pacífico CMP.

Conflicts of Interest: The authors declare no conflict of interest.

\section{References}

1. Compañía Minera del Pacífico (CMP). Memoria Anual 2019. 2020. Available online: www.cmp.cl (accessed on 10 March 2021).

2. Cochilco. Anuario de Estadísticas del Cobre y Otros Minerales 2000-2019. Corporación Chilena del Cobre. 2020. Available online: www.cochilco.cl (accessed on 10 March 2021).

3. Krieger, I.M.; Maron, S.H. Direct Determination of the Flow Curves of Non-Newtonian Fluids. J. Appl. Phys. 1952, 23, 147-149. [CrossRef]

4. Krieger, I.M.; Elrod, H. Direct Determination of the Flow Curves of Non-Newtonian Fluids. II. Shearing Rate in the Concentric Cylinder Viscometer. J. Appl. Phys. 1953, 24, 134-136. [CrossRef]

5. Krieger, I.M.; Maron, S.H. Direct Determination of the Flow Curves of Non-Newtonian Fluids. III. Standardized Treatment of Viscometric Data. J. Appl. Phys. 1954, 25, 72. [CrossRef]

6. Krieger, I.M.; Woods, E. Direct determination of the flow curves of non Newtonian fluids. IV. Parallel plane rotational viscometer. J. Appl. Phys. 1966, 37, 4703-4704.

7. Jacobsen, R. The determination of the flow curve of a plastic medium in a wide gap rotational viscometer. J. Colloid Interface Sci. 1974, 48, 437-441. [CrossRef]

8. Fisher, D.T.; Clayton, S.A.; Boger, D.V.; Scales, P.J. The bucket rheometer for shear stress-shear rate measurement of industrial operation. J. Rheol. 2007, 51, 821-831. [CrossRef] 
9. Casson, N. A flow equation for pigment-oil suspensions of the printing ink type. In Rheology of Dispersed Systems; Mill, C.C., Ed.; Pergamon Press: New York, NY, USA, 1959; p. 84.

10. Klein, B. Rheology and Stability of Magnetite Dense Media. Ph.D. Thesis, The University of British Columbia, Vancouver, BC, Canada, 1992.

11. Nguyen, Q.D.; Boger, D.V. Yield stress measurement for concentrated suspensions. J. Rheol. 1983, 27, $321-349$.

12. Nguyen, Q.D.; Boger, D.V. Direct yield stress measurement with the vane method. J. Rheol. 1985, $29,335-347$.

13. Keentok, M. The measurement of the yield stress of liquids. Rheol. Acta 1982, 21, 325-332. [CrossRef]

14. Barnes, H.A.; Walters, K. The yield stress myth? Rheol. Acta 1985, 24, 323-326. [CrossRef]

15. Utracki, L.A. The rheology of two-phase flows. In Rheological Measurement; Collyer, A.A., Clegg, D.W., Eds.; Elsevier: London, UK, 1988; pp. 479-594.

16. Goldsmith, H.; Mason, S. The flow of suspensions through tubes. I. Single spheres, rods, and discs. J. Colloid Sci. 1962, 17, 448-476. [CrossRef]

17. Goldsmith, H.L.; Mason, S.G. The Microrheology of Dispersions. In Proceedings of the 4th International Congress on Rheology, Providence, RI, USA, 26-30 August 1963; Eirich, F.R., Ed.; John Wiley and Son: New York, NY, USA, 1967; pp. 85-250.

18. Uribe, L.; Gutierrez, L.; Jerez, O. The Depressing Effect of Clay Minerals on the Floatability of Chalcopyrite. Miner. Process. Extr. Met. Rev. 2016, 37, 227-235. [CrossRef]

19. Uribe, L.; Gutiérrez, L.; Laskowski, J.; Castro, S. Role of calcium and magnesium cations in the interactions between kaolinite and chalcopyrite in seawater. Physicochem. Probl. Miner. Process. 2017, 53, 737-749.

20. Ndlovu, B.; Farrokhpay, S.; Bradshaw, D. The effect of phyllosilicate minerals on mineral processing industry. Int. J. Miner. Process. 2013, 125, 149-156. [CrossRef]

21. Ndlovu, B.; Forbes, E.; Farrokhpay, S.; Becker, M.; Bradshaw, D.; Deglon, D. A preliminary rheological classification of phyllosilicate group minerals. Miner. Eng. 2014, 55, 190-200. [CrossRef]

22. Ralston, J.; Fornasiero, D.; Grano, S.; Duan, J.; Akroyd, T. Reducing uncertainty in mineral flotation-Flotation rate constant prediction for particles in an operating plant ore. Int. J. Miner. Process. 2007, 84, 89-98. [CrossRef]

23. Cruz, N.; Peng, Y.; Farrokhpay, S.; Bradshaw, D. Interactions of clay minerals in copper-gold flotation: Part 1-Rheological properties of clay mineral suspensions in the presence of flotation reagents. Miner. Eng. 2013, 50-51, 30-37. [CrossRef]

24. McFarlane, A.; Bremmell, K.; Addai-Mensah, J. Microstructure, rheology and dewatering behaviour of smectite dispersions during orthokinetic flocculation. Miner. Eng. 2005, 18, 1173-1182. [CrossRef]

25. Bakker, C.; Meyer, C.; Deglon, D. Numerical modelling of non-Newtonian slurry in a mechanical flotation cell. Miner. Eng. 2009, 22, 944-950. [CrossRef]

26. Klein, C.; Hurlbut, C.S., Jr. Manual of Mineralogy (after James D. Dana), 21st ed.; Wiley: Hoboken, NJ, USA, 1993.

27. Swartzen-Allen, S.L.; Matijevic, E. Surface and colloid chemistry of clays. Chem. Rev. 1974, 74, 385-400. [CrossRef]

28. Gungor, N. Effect of the adsorption of surfactants on the rheology of Nabentonite slurries. J. Appl. Polym. Sci. 2000, 75, 107-110. [CrossRef]

29. Paineau, E.; Michot, L.J.; Bihannic, I.; Baravian, C. Aqueous Suspensions of Natural Swelling Clay Minerals. 2. Rheological Characterization. Langmuir 2011, 27, 7806-7819. [CrossRef]

30. Brigatti, M.; Galán, E.; Theng, B. Structure and Mineralogy of Clay Minerals. In Handbook of Clay Science; Beggaya, F., Theng, B.K.G., Lagaly, G., Eds.; Elsevier: Amsterdam, The Netherlands, 2006; pp. 19-86.

31. Lagaly, G.; Ziesmer, S. Colloid chemistry of clay minerals: The coagulation of montmorillonite dispersions. Adv. Colloid Interface Sci. 2003, 100-102, 105-128. [CrossRef]

32. Ran, B.; Melton, I.E. Particle Interactions in Aqueous Kaolinite Suspensions: I. Effect of pH and Electrolyte upon the Mode of Particle Interaction in Homoionic Sodium Kaolinite Suspensions. J. Colloid Interface Sci. 1977, 60, 308-320.

33. Miller, J.D.; Nalaskowski, J.; Abdul, B.; Du, H. Surface characteristics of kaolinite and other selected two layer silicate minerals. Can. J. Chem. Eng. 2007, 85, 617-624. [CrossRef]

34. Vanerek, A.; Alince, B.; van de Ven, T.G.M. Delamination and flocculation efficeincy of sodium activated kaolin and montmorillonite. Colloids Surf. A Physicochem. Eng. Asp. 2006, 273, 193-201. [CrossRef]

35. Hu, Y.; Wei, S.; Hao, J.; Miller, J.; Fa, K. The anomalous behavior of kaolinite flotation with dodecyl amine collector as explained from crystal structure considerations. Int. J. Miner. Process. 2005, 76, 163-172. [CrossRef]

36. Johnson, S.B.; Russell, A.S.; Scales, P.J. Volume Fraction Effects in Shear Rheology and Electroacoustic Studies of Concentrated Alumina and Kaolin Suspensions. Colloids Surf. A Physicochem. Eng. Asp. 1998, 141, 119-130. [CrossRef]

37. Bickmore, B.R.; Nagy, K.L.; Sandlin, P.E.; Crater, T.S. Quantifying surface areas of clays by atomic force microscopy. Am. Miner. 2002, 87, 780-783. [CrossRef]

38. Brady, P.V.; Cygan, R.T.; Nagy, K.L. Molecular Controls on Kaolinite Surface Charge. J. Colloid Interface Sci. 1996, 183, 356-364. [CrossRef] 